\title{
Poly(perfluoroalkyl methacrylate) Film Structures: Surface Organization Phenomena, Surface Energy Determinations, and F orce of Adhesion Measurements
}

\author{
J ohn Tsibouklis,* Paul Graham, Peter J . Eaton, J ames R. Smith, \\ Thomas G. Nevell, J ohn D. Smart, and Richard J . E wen ${ }^{\dagger}$
}

School of Pharmacy and Biomedical Sciences, University of Portsmouth, St. Michael's Building, White Swan Road, Portsmouth PO1 2DT, UK.

Received May 12, 2000; Revised Manuscript Received August 9, 2000

\begin{abstract}
The significance of the Liftshitz/van der Waals, Lewis-acid, and Lewis-base contributors to the total surface energy of a homologous series of poly(perfluoroalkyl methacrylate)s is discussed in terms of the molecular design features and surface organization phenomena characterizing these polymeric compounds. The study suggests that, of the molecular design requirements for low-surface-energy polymers, a flexible backbone is not an essential feature.
\end{abstract}

\section{Introduction}

One of the strategies that have emerged as potential means of inhibiting the early stages of bi ofilm formation invol ves the utilization of low-surface-energy polymeric coatings. ${ }^{1-4}$

The surface energy $(\gamma)$ of a material is expressed by ${ }^{5}$ $\gamma=\gamma^{\circ} \rho^{\beta}\left(\gamma^{\circ}\right.$ and $\beta$ are temperature-independent constants, and $\rho$ is the specific gravity of the material). For polymeric materials, the value of $\gamma^{\circ}$ is determined mainly by the chemical structure at the surface: it is established that the surface energy of constituent groups decreases in the order $\mathrm{CH}_{2}\left(36 \mathrm{mNm}^{-1}\right)>\mathrm{CH}_{3}$ $\left(30 \mathrm{mNm}^{-1}\right)>\mathrm{CF}_{2}\left(23 \mathrm{mNm}^{-1}\right)>\mathrm{CF}_{3}\left(15 \mathrm{mNm}^{-1}\right){ }^{6-9}$ The value of $\beta$ (the Macleod exponent), which is normally in the range 3.0-4.5, is determined by the overall structure of the macromolecule. Finally, the entropy of the surface is of some significance: amorphous materials exhibit lower surface energy values than crystalline counterparts. ${ }^{10}$ It has been suggested that amorphous, comblike polymers possessing a flexible linear backbone, onto which are attached side chains with low intermolecular interactions, will exhibit low $\gamma$ values. ${ }^{11}$

As part of our work on new polymers with lowsurface-energy properties, we have recently reported on the synthesis, characterization, film-forming characteristics, and surface energies of two classes of materials that may comply with the molecular design requirements imposed by the above considerations, namely, the poly(perfluoroalkyl acrylate)s ${ }^{12-16}$ and the poly(methylpropenoxyperfluoroal kylsiloxane)s. ${ }^{17} \mathrm{~F}$ or purposes of comparison, certain hydrocarbon analogues, poly(octyl acrylate) and poly(methylpropenoxyal kylsiloxane)s, of the same classes of materials were also studied. ${ }^{18}$ Consideration of the surface energy components associated with each member of the above classes of materials revealed that, in addition to surface roughness (the effects of which can be assessed from measurements of contact-angle hysteresis, i.e., the difference between advancing and receding contact angles), the wetting

\footnotetext{
* Corresponding author: Tel ++44 (0)2392 84 3606; fax ++44 (0)2392 84 3565; e-mail john.tsibouklis@port.ac.uk.

${ }^{\dagger}$ F aculty of Applied Sciences, University of the West of England, Frenchay Campus, Coldharbour Lane, Bristol BS16 1QY, U.K.
}

behavior is determined by the nature of the pendent chain, the length of the pendent chain, the nature of the linking moiety, and the nature of the polymer backbone. ${ }^{19}$ In particular, comparison of the total surface energy values characterizing the four homologous series of macromolecules highlighted the relative significance of fluoro substitution and backbone flexibility for the construction of low-surface-energy polymers. Typically, the more flexible fluorosiloxanes exhibited higher surface energy values (ca. $12-17 \mathrm{~mJ} \mathrm{~m}^{-2}$ for $\mathrm{n}$ = 3-9) than their acrylate counterparts (ca. 6-13 mJ $\mathrm{m}^{-2}$ for $\mathrm{n}=3-9$ ); the same effect, although less pronounced, was observed with the nonfluorinated materials. ${ }^{12-19}$ This behavior, which is in marked contrast to expectation on the basis of previous literature reports, ${ }^{2,11}$ may be rationalized at the submol ecular level in terms of two possible phenomena. First, thermal cross-linking may make the polysiloxane backbone more rigid than that of polyacrylates; it was found that the surface energy of a thermally cross-linked fluorosilicone was ca. $3 \mathrm{~mJ} \mathrm{~m} \mathrm{~m}^{-2}$ greater than that of a parallel sample which had not been so treated. ${ }^{17}$ Second, the two classes of materials display different molecular organization characteristics at the interface. Data from X-ray photoel ectron spectroscopy experiments on film structures prepared using the higher fluorosilicones indicated that, for these materials, there is a preferential distribution of the siloxane backbone nearer to the surface with the pendent perfluorocarbon chains oriented toward the bulk of the sample. By contrast, however, the surface arrangements of the poly(perfluoro acrylate)s appeared to be such that the perfluorocarbon side chains segregate preferentially at the surface. ${ }^{19,20}$

We now attempt to examine the relationship between backbone flexibility and surface energy by considering a further class of low-surface-energy materials, namely, the poly(perfluoroalkyl methacrylate)s.

\section{Experimental Section}

2.1. Materials. The readily accessible monomers were polymerized, in the bulk ( $1 \% \mathrm{w} / \mathrm{w}$ AIBN, $\left.60^{\circ} \mathrm{C}\right)$, to give the corresponding poly(perfluoroalkyl methacrylate)s (Figure 1); the corresponding poly(alkyl methacrylate)s were also pre pared. The polymers were purified by repeated washings in diethyl ether and dried under reduced pressure. 


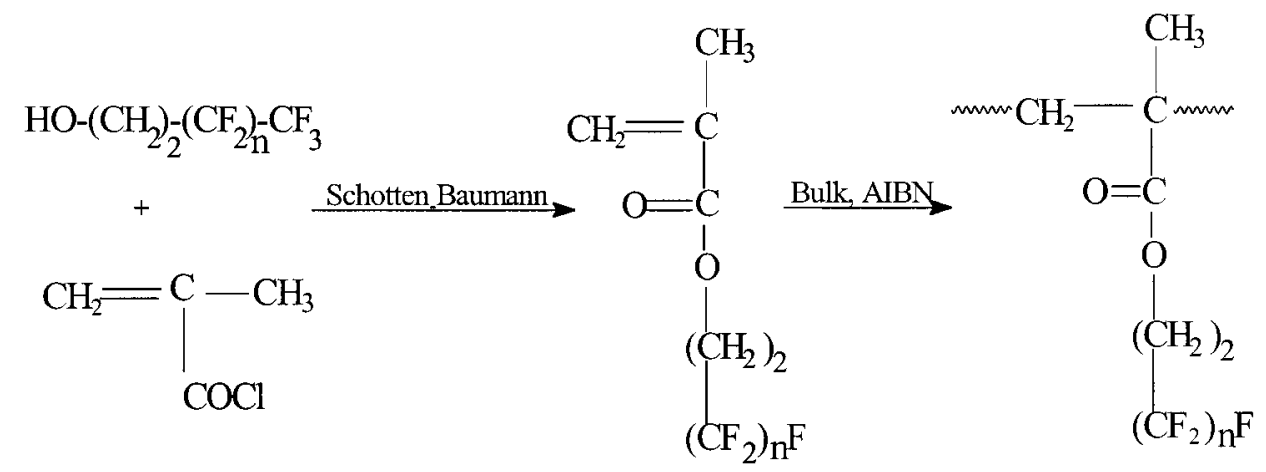

Figure 1. Reaction scheme for the synthesis of poly $(1 \mathrm{H}, 1 \mathrm{H}, 2 \mathrm{H}, 2 \mathrm{H}$-perfluoroalkyl methacrylate)s: $\mathrm{n}=4$ (PFHMA; poly$(1 \mathrm{H}, 1 \mathrm{H}, 2 \mathrm{H}, 2 \mathrm{H}$-perfluorohexyl methacrylate)), $n=6$ (PFOMA; poly $(1 \mathrm{H}, 1 \mathrm{H}, 2 \mathrm{H}, 2 \mathrm{H}$-perfluorooctyl methacrylate)), $n=8$ (PFDMA; poly $(1 \mathrm{H}, 1 \mathrm{H}, 2 \mathrm{H}, 2 \mathrm{H}$-perfluorodecyl methacrylate)), $\mathrm{n}=10$ (PFDDMA; poly $(1 \mathrm{H}, 1 \mathrm{H}, 2 \mathrm{H}, 2 \mathrm{H}$-perfluorododecyl methacrylate)). The corresponding poly(alkyl methacrylate)s were also prepared.

The fluorinated polymers were found to be insoluble in common organic solvents but could be dissolved in $1,1,2$ trichlorotrifluoroethane and 1,1,1,3,3,3-hexafluoropropan-2-ol Poly(alkyl methacrylate) congeners, prepared under identical conditions, exhibited average molecular weight distributions of the order of $1 \times 10^{5}-2 \times 10^{5}$, relative to polystyrene standards, as demonstrated by gel permeation chromatography experiments in tetrahydrofuran.

2.2. Film Formation. Films of these materials were deposited from the melt or from $\mathrm{CF}_{2} \mathrm{ClCFCl}_{2}(0.1 \% \mathrm{w} / \mathrm{w})$ solution (dipping speed: $1 \mathrm{~mm} \mathrm{~s}^{-1}$ ) onto Teflon and/or poly(methyl methacrylate) supporting substrates $(10 \times 10 \times 1$ $\mathrm{mm}$ ). Ellipsometric determinations on films deposited onto the latter substrate showed the solution-deposited films had a thickness of the order of $250 \mathrm{~nm}$; melt-deposited structures were found to be in the range $1-3 \mu \mathrm{m}$.

2.3. Atomic Force Microscopy. Adhesion and surface roughness measurements were performed using a TopoM etrix Discoverer TMX2000 scanning probe microscope (ThermoMicroscopes, Bicester, UK). Triangular, standard-profile $\mathrm{Si}_{3} \mathrm{~N}_{4}$ cantilevers (length $200 \mu \mathrm{m}$ ) of nominal spring constant 0.032

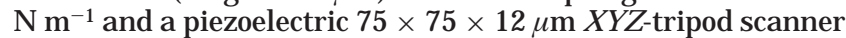
were used. Surface roughness measurements, expressed in terms of the roughness average, $R_{a}$, were obtained by imaging polymer surfaces over a scan area of $50 \times 50 \mu \mathrm{m}^{2}$ in air and applying a digital leveling algorithm.

Adhesion between the $\mathrm{Si}_{3} \mathrm{~N}_{4}$ tip and polymer surfaces was measured in water (Sigma-Aldrich Chemical Co., UK; $18 \mathrm{M} \Omega$, $0.2 \mu \mathrm{m}$ filtered) by recording the deflection of the cantilever at the point where the tip detached from the surface during the retraction regime of the force-distance curve. This "pulloff" deflection (nA) was converted to a force of adhesion ( $\mathrm{nN}$ ) using the sensor response obtained from each force curve and the actual measured spring constant of the cantilever. The acquisition of adhesion data from force curves was automated through the use of an in-house program written in Quick Basic. Adhesion studies were performed in water to eliminate the presence of capillary forces caused by adsorbed water films when working in air. ${ }^{21}$ To minimize errors associated with tip geometries and variations in cantilever spring constants, the same AFM probe was used for all experiments. For each polymer sample, 135 adhesion measurements were obtained from 45 force curves in each of three separate areas.

2.4. AF M Cantilever Calibration. Spring constants were determined, using a mild adaptation of Cleveland's method, ${ }^{22}$ by measuring the cantilever's natural resonant frequency after the attachment of small end masses:

$$
\mathrm{M}=\mathrm{k}(2 \pi v)^{-2}-\mathrm{m}^{*}
$$

where $M$ is the total end mass of one or more attached microspheres $(\mathrm{kg}), \mathrm{m} *$ is the mass of the unloaded cantilever $(\mathrm{kg}), v$ is the resonant frequency of the loaded cantilever $(\mathrm{Hz})$, and $\mathrm{k}$ is the spring constant of the cantilever $\left(\mathrm{N} \mathrm{m}^{-1}\right)$.
A plot of $M$ vs $1 /(2 \pi v)^{2}$ gave a straight line with a gradient equal to the actual spring constant, $\mathrm{k}$ : in this case, $0.034 \pm$ $0.001 \mathrm{~N} \mathrm{~m}^{-1}$. In contrast to Cleveland's work, which utilized polydisperse tungsten microspheres, ${ }^{22}$ monodisperse polystyrene microspheres (diameter $40.25 \pm 0.32 \mu \mathrm{m}$; Duke Scientific Corp., CA) were attached to the tip using a small amount of UV-cure glue. The adopted procedure eliminated the need for time-consuming measurements of particle diameters, thereby improving accuracy and precision. It is worth noting that, in order to confirm that there was no mass change, the resonant frequency of the cantilever was determined before and after each adhesion measurement as a matter of routine.

2.5. Goniometry. The surface free energies of polymer samples were determined by contact angle goniometry in a thermostated cell $\left(25 \pm 1^{\circ} \mathrm{C}\right)$ using a Kruss G10 goniometer interfaced to image capture software ${ }^{12}$ Both advancing $\left(\theta_{\mathrm{A}}\right)$ and receding $\left(\theta_{R}\right)$ contact angles were measured for droplets $(2-10 \mu \mathrm{L})$ of doubly distilled water, diiodomethane, n-hexadecane, and 1,2-ethanedi ol.23,24 In the case of receding contact angle experiments, a drop of the probing liquid $(8-10 \mu \mathrm{L})$ was placed on the surface of the sample and subsequently removed in small increments $(0.5 \mu \mathrm{L})$ until the drop edge spontaneously contracted to a new stationary position at which the receding contact angle was measured. Hysteresis $(\mathrm{H})$ was recorded as $\left(\theta_{\mathrm{A}}-\theta_{\mathrm{R}}\right)$. The nature of the supporting substrate (PTFE, glass, PMMA) was found to be of no influence on the wetting behavior exhibited by the perfluoroalkyl methacrylate film structures under consideration.

2.6. Surface E nergy Calculations. Surface energies were evaluated using the surface-tension-component theory. ${ }^{25,26}$ According to this approach, the surface energy of a solid, $\gamma_{s}$, combines the Liftshitz/van der Waals component, $\gamma^{\mathrm{LW}}$, the Lewis-acid component, $\gamma^{+}$, and the Lewis-base component, $\gamma^{-}$ (eq 2):

$$
\gamma_{\mathrm{S}}=\gamma_{\mathrm{S}}^{\mathrm{LW}}+\left(\gamma_{\mathrm{S}}^{+} \gamma_{\mathrm{S}}^{-}\right)^{1 / 2}
$$

For a drop of a liquid at equilibrium with a solid surface, the liquid-solid contact angle $(\theta)$ is given by eq 3 :

$\gamma_{\mathrm{L}}(1+\cos \theta)=2\left[\left(\gamma_{\mathrm{S}}^{\mathrm{LW}} \gamma_{\mathrm{L}}^{\mathrm{LW}}\right)^{1 / 2}+\left(\gamma_{\mathrm{S}}^{+} \gamma_{\mathrm{L}}^{-}\right)^{1 / 2}+\left(\gamma_{\mathrm{S}}^{-} \gamma_{\mathrm{L}}^{+}\right)^{1 / 2}\right]$

where $\gamma_{\mathrm{L}}$ is the surface tension of the liquid and subscripts $\mathrm{S}$ $=$ solid and $\mathrm{L}=$ liquid. Hence, by measuring contact angles for three well-characterized (in terms of $\gamma_{\mathrm{L}}^{\mathrm{LW}}, \gamma_{\mathrm{L}}^{+}$, and $\left.\gamma_{\mathrm{L}}^{-}\right)^{23,24}$ liquids, three equations with three unknowns are generated; water, diiodomethane, and ethylene glycol were employed; and, following van Oss et al.,25,26 values of $\theta_{\text {A }}$ were used. For comparison, the surface energy of poly(tetrafluoroethylene), Teflon, was determined as $21 \mathrm{~mJ} \mathrm{~m}^{-2}$, and for polyethylene a value of $30 \mathrm{~mJ} \mathrm{~m} \mathrm{~m}^{-2}$ was obtained. ${ }^{27}$

2.7. X-ray Photoelectron Spectroscopy (XPS). XPS was carried out using a VG Scientific ESCALAB Mk.II instrument employing a nonmonochromatized Al K $\alpha$ source (1486.6 eV) 


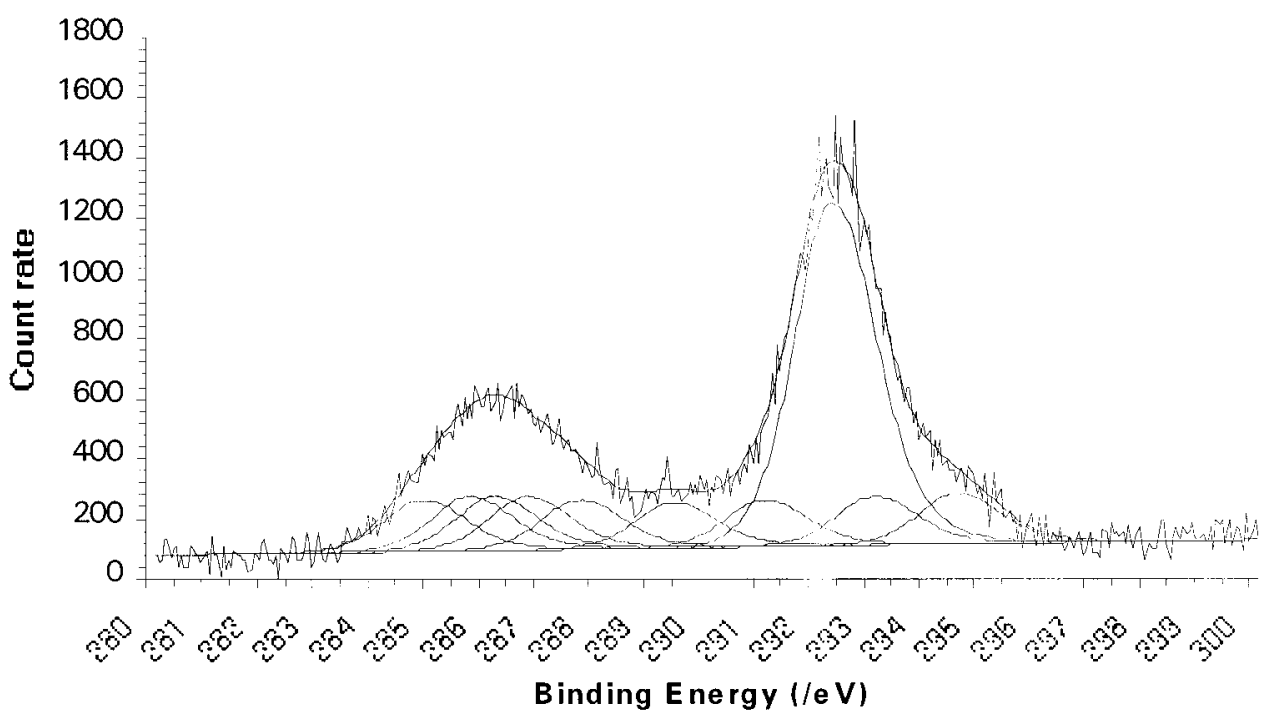

Figure 2. Typical least-squares curve fitting analysis: the $C$ ls spectrum for poly $(1 \mathrm{H}, 1 \mathrm{H}, 2 \mathrm{H}, 2 \mathrm{H}$-perfluorododecyl methacrylate), PFDDMA. (All fitted peaks have a fwhm of $1.60 \mathrm{eV}$; peak positions and relative percentages are given in Table 1.)

Table 1. Binding Energies and Atomic Proportions of Elements at the Surface of Melt-Formed Poly(perfluoroalkyl methacrylate) Film Structuresa

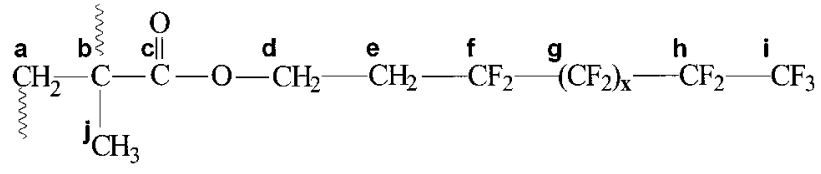

\begin{tabular}{|c|c|c|c|c|c|c|c|c|c|c|c|c|c|c|}
\hline \multirow[b]{2}{*}{ element } & \multirow[b]{2}{*}{ carbon } & \multicolumn{3}{|c|}{ PFHMA } & \multicolumn{3}{|c|}{ PFOMA } & \multicolumn{3}{|c|}{ PFDMA } & \multicolumn{3}{|c|}{ PFDDMA } & \multirow[b]{2}{*}{ assignt } \\
\hline & & $\mathrm{N}^{\mathrm{b}}$ & $\begin{array}{l}E_{b} / \\
e V\end{array}$ & $\begin{array}{l}\text { atomic \% } \\
\text { found } \\
\text { (calc) }\end{array}$ & $\mathrm{N}$ & $E_{b} / e V$ & $\begin{array}{l}\text { atomic \% } \\
\text { found } \\
\text { (calc) }\end{array}$ & $\mathrm{N}$ & $E_{b} / e V$ & $\begin{array}{l}\text { atomic \% } \\
\text { found } \\
\text { (calc) }\end{array}$ & $\mathrm{N}$ & $\mathrm{E}_{\mathrm{b}} / \mathrm{eV}$ & $\begin{array}{l}\text { atomic \% } \\
\text { found } \\
\text { (calc) }\end{array}$ & \\
\hline$C(1 s)$ & a & 1 & 285.0 & $4.1(4.8)$ & 1 & 285.0 & $3.0(3.7)$ & 1 & 285.0 & $2.8(3.0)$ & 1 & 285.0 & $2.6(2.6)$ & $\begin{array}{l}-\mathrm{CH}_{2}-\mathrm{C}- \\
\text { backbone }\end{array}$ \\
\hline$C(1 s)$ & e & 1 & 285.6 & $4.1(4.8)$ & 1 & 285.5 & $4.0(3.7)$ & 1 & 285.6 & $2.9(3.0)$ & 1 & 285.9 & $2.7(2.6)$ & $-\mathrm{CH}_{3}$ \\
\hline C(1s) & b & 1 & 285.8 & $3.9(4.8)$ & 1 & 286.0 & $3.6(3.7)$ & 1 & 286.2 & $2.7(3.0)$ & 1 & 286.3 & 2.7 (2.6) & $\begin{array}{l}-\mathrm{CH}_{2}-\mathrm{C}- \\
\text { backbone }\end{array}$ \\
\hline$C(1 s)$ & d & 1 & 286.7 & $3.7(4.8)$ & 1 & 286.6 & $3.8(3.7)$ & 1 & 286.6 & $2.7(3.0)$ & 1 & 286.9 & $2.6(2.6)$ & $-\mathrm{O}-\mathrm{CH}_{2}-$ \\
\hline$C(1 s)$ & j & 1 & 287.5 & $4.1(4.8)$ & 1 & 287.5 & $3.1(3.7)$ & 1 & 287.6 & $3.1(3.0)$ & 1 & 287.9 & $2.5(2.6)$ & $\begin{array}{l}-\mathrm{CH}_{2}-\mathrm{CH}_{2}- \\
\mathrm{CF}_{2}-\end{array}$ \\
\hline$C(1 s)$ & C & 1 & 289.4 & $5.0(4.8)$ & 1 & 289.2 & $2.8(3.7)$ & 1 & 289.4 & $2.3(3.0)$ & 1 & 289.6 & $2.3(2.6)$ & $-\mathrm{O}-\mathrm{C}=\mathrm{O}$ \\
\hline C(1s) & $f$ & 1 & 292.0 & $6.4(4.8)$ & 1 & 292.1 & $1.6(3.7)$ & 1 & 292.2 & $2.6(3.0)$ & 1 & 292.5 & $2.3(2.6)$ & $\begin{array}{l}-\mathrm{CH}_{2}-\mathrm{CH}_{2}- \\
\mathrm{CF}_{2}-\end{array}$ \\
\hline$C(1 s)$ & g & 1 & 291.5 & $4.6(4.8)$ & 3 & 290.9 & 13.8 (11.1) & 5 & 290.9 & 16.1 (15.2) & 7 & 291.2 & 16.7 (17.9) & $-\left(\mathrm{CF}_{2}\right)_{x}-$ \\
\hline$C(1 s)$ & $\mathrm{h}$ & 1 & 292.2 & $3.5(4.8)$ & 1 & 293.2 & 3.0 (3.7) & 1 & 293.0 & $1.9(3.0)$ & 1 & 293.2 & $2.4(2.6)$ & $-\mathrm{CF}_{2}-\mathrm{CF}_{3}$ \\
\hline$C(1 s)$ & i & 1 & 294.3 & $3.6(4.8)$ & 1 & 294.3 & 3.0 (3.7) & 1 & 294.5 & $2.4(3.0)$ & 1 & 294.7 & $2.5(2.6)$ & $-\mathrm{CF}_{3}$ \\
\hline$F(1 s)$ & & 9 & 689.6 & 49.5 (42.9) & 13 & 689.6 & 51.2 (48.1) & 17 & 689.7 & 54.7 (51.5) & 21 & 690.0 & $55.9(53.8)$ & \\
\hline $\mathrm{O}(1 \mathrm{~s})$ & & 1 & 532.9 & $3.8(4.8)$ & 1 & 532.9 & $3.7(3.7)$ & 1 & 533.1 & $3.0(3.0)$ & 1 & 533.2 & $2.5(2.6)$ & $-\mathrm{O}-\mathrm{CH}_{2}-$ \\
\hline$O(1 s)$ & & 1 & 534.3 & $3.7(4.8)$ & 1 & 534.3 & $3.6(3.7)$ & 1 & 534.5 & $2.8(3.0)$ & 1 & 534.9 & 2.5 (2.6) & $\mathrm{C}=\mathrm{O}$ \\
\hline
\end{tabular}

a The differences in the chemical structures of polymers PFHMA, PFOMA, PFDMA, and PFDDMA are explained in Figure $1 .{ }^{b}$ Number of atoms.

and operating at a power of $125 \mathrm{~W}$ (some test samples were found to exhibit slight degradation after $40 \mathrm{~min}$ exposure to an X-ray beam operating at $250 \mathrm{~W}$; sample degradation at 125 W was found to be negligible) according to the following procedure: (a) fast (30 s) scan of the $\mathrm{C}$ 1s region $(\mathrm{C}-\mathrm{C}, \mathrm{C}-\mathrm{O}$, and CF); (b) full set of scans at a $75^{\circ}$ takeoff angle (approximately $20 \mathrm{~min}$ ); and (c) repeat of (a). Comparison of the relative areas of the $C$ 1s peaks from the scans in (a) and (c) allowed the determination of the relative percentages of carbon bonded to fluorine versus carbon not bonded to fluorine, and after curvefitting, dehal ogenation was shown to be negligible. The analyzer was operated at a constant pass energy of 20 eV. Line shape analysis was performed on each peak, and atomic percentages were cal culated from the peak areas using standard atomic sensitivity factors. ${ }^{28}$ All peaks were fitted using a fwhm of $1.60 \mathrm{eV}$ (Figure 2). The depth of sampling was not determined.

\section{Results and Discussion}

3.1. XPS Studies. In contrast to previous work with other compounds of this type, 13,20 comparison of the observed surface concentration of atoms with cal culated bulk concentration of poly(perfluoroalkyl methacrylate) samples (Table 1) appears to provide only a mild indication that the perfluorocarbon side chains have a slight bias for the surface. Specifically, the atomic percentages of the two types of backbone carbon, $-\mathrm{CH}_{2}-$ $\mathrm{C}-$, are generally lower than those calculated for the bulk sample whereas the atomic percentages for fluorine, which is associated with the sidechain, are slightly enhanced. Analogous trends are seen for side-chain carbon and linking-group oxygen. However, these effects become less pronounced and fall outside the resolution 
Table 2. Surface Roughness $\left(R_{\mathrm{a}}\right)$ and Advancing Contact Angles for Water, Diiodomethane (DIM), and Ethylene Glycol (EG) on Poly(perfluoroalkyl methacrylate) Film Structures Formed from the Melt; Surface Energies, As Determined from Advancing-Contact-Angle Measurements, Are Also Presented ${ }^{a}$

\begin{tabular}{|c|c|c|c|c|c|c|c|c|}
\hline \multirow[b]{2}{*}{ sample } & \multirow[b]{2}{*}{$\mathrm{R}_{\mathrm{a}} / \mathrm{nm}$} & \multicolumn{3}{|c|}{ contact angle, $\theta / \mathrm{deg}(\mathrm{H} / \mathrm{deg})$} & \multicolumn{4}{|c|}{ surface energy/mJ $\mathrm{m}^{-2}$} \\
\hline & & $\mathrm{H}_{2} \mathrm{O}$ & DIM & EG & $\gamma_{\mathrm{S}}^{\mathrm{LW}}$ & $\gamma_{\mathrm{S}}^{+}$ & $\gamma_{\mathrm{s}}^{-}$ & $\gamma_{\mathrm{S}}$ \\
\hline PFDDMA & 7.13 & $125(6)$ & 109 (13) & 107 (34) & $5.8 \pm 0.3$ & $0.3 \pm 0.0$ & $0.1 \pm 0.0$ & $6.1 \pm 0.4$ \\
\hline PFDMA & 1.17 & $124(9)$ & 104 (12) & 105 (19) & $7.3 \pm 0.4$ & $0.2 \pm 0.0$ & $0.1 \pm 0.0$ & $7.5 \pm 0.4$ \\
\hline PFOMA & 0.41 & 121 (33) & 104 (29) & $106(29)$ & $7.3 \pm 0.4$ & $0.1 \pm 0.0$ & $0.5 \pm 0.0$ & $7.7 \pm 0.5$ \\
\hline PFHMA & 0.29 & $123(35)$ & 103 (11) & 102 (17) & $7.6 \pm 0.3$ & $0.3 \pm 0.0$ & $0.0 \pm 0.0$ & $7.8 \pm 0.4$ \\
\hline
\end{tabular}

a Each contact angle value is the mean of six drops on two independently prepared polymer samples. The surface energy of a relatively rough film $\left(R_{a} \gg 100 \mathrm{~nm}\right)$ of the nonfluorinated analogue of PFDDMA, poly(dodecyl methacrylate) (PDDMA), was also evaluated for comparison: 41 advancing-contact-angle data yiel ded a value of $11 \mathrm{~mJ} \mathrm{~m} \mathrm{~m}^{-2}$, whereas the use of the receding-contact-angle value determined the same parameter at $48 \mathrm{~mJ} \mathrm{~m} \mathrm{~m}^{-2}$. The chemical structures of polymers PFHMA, PFOMA, PFDMA, and PFDDMA are shown in Figure 1.

limits of our instrument, for film samples of the higher homologues. This may reflect chain interpenetration but could, also, be due to the decreased sensitivity of the comparison, resulting from the increasing ratio of sidechain atoms to backbone atoms. Thus, it is important to note that the XPS data cannot be taken as conclusive evidence for surface enrichment as the observed differences are positioned at the limits of meaningfulness.

3.2. Surface Energies. Dependent upon the length of the pendent perfluorocarbon chain, the surface free energies of the melt formed poly(perfluoroalkyl methacrylate) films under consideration were of the order of 6-8 m m $\mathrm{m}^{-2}$, with the higher homologue, poly $(1 \mathrm{H}, 1 \mathrm{H}, 2 \mathrm{H}$, $2 \mathrm{H}$-perfluorododecyl methacrylate), exhibiting the lower value (Table 2). The extremely low surface energies associated with these poly $(1 \mathrm{H}, 1 \mathrm{H}, 2 \mathrm{H}, 2 \mathrm{H}$-perfluoroal kyl methacrylate)s indicate very little affinity for the probing liquids used, and the suppressed values of the individual contributors to the total surface energy of the homologous series of methacrylates considered are highlighted. In particular, the Liftshitz/van der Waals components $\left(\gamma_{\mathrm{S}}^{\mathrm{LW}}\right)$ are among the lowest reported for polymeric materials, ${ }^{2,12-19}$ whereas the contributions of the Lewis acid $\left(\gamma_{\mathrm{s}}^{+}\right)$and Lewis base $\left(\gamma_{\mathrm{s}}^{-}\right)$components to the total surface energy are negligible in all cases. Characteristically, the longer chain analogue (PFDDMA) exhibits the lowest $\gamma_{S}^{\mathrm{LW}}$ values. Since the lowest energy surfaces are those containing perfluoroalkyl groups that are oriented to yield exposed $-\mathrm{CF}_{3}$ moieties, ${ }^{29}$ the observed surface organization phenomena connoted by XPS (Table 1) are consistent with the trends in surface energy values.

As with all homologous series of other materials considered to date, ${ }^{19}$ the results presented in Table 2 reveal a mild trend toward lower surface energy with increasing chain length. However, as the length of the pendent chain increases, so also does the average surface roughness of the film structures. This effect, which is particularly pronounced with the higher homologues (PFDDMA and PFDMA), is also reflected by the observed hysteresis values $(\mathrm{H})$ and is considered to be the prime reason for the differences in contact angles observed between adjacent members of the homologous series. To verify this assumption, a series of goni ometry experiments were performed on a solution-deposited film of PFDDMA with an AFM-determined $R_{a}$ value of $73.5 \mathrm{~nm}$ : contact angles of $153^{\circ}$ and $149^{\circ}$ were measured for diiodomethane and ethylene glycol, respectively, whereas drops of water were seen to give contact angles close to $180^{\circ}$, such that they could not be detached from the microcapillary pipet used to deliver this liquid onto the surface. Comparison of the contact angle values associated with the relatively rough surfaces deposited from solution with those of corresponding films prepared in the melt (Table 2) emphasizes the relationship between surface roughness and wettability. Nonetheless, the incorporation of a long perfluorocarbon side chain is an essential element of the molecular design for such materials, as it serves to inhibit the absorption of liquids by the bulk sample. Indeed, the time-independent surface energy values (monitored over 30 min by observing the dimensions of liquid drops on each surface) associated with the higher homologues (PFDDMA and PFDMA) confirmed that the probing liquids do not become absorbed into the bulk sample. ${ }^{12,17-19}$

Receding contact angles were also measured for all materials. For the higher analogues, PFDDMA and PFDMA, the observed hysteresis (Table 2) is attributed to surface roughness effects whereas that associated with the PFOMA and PFHMA is primarily due to penetration of the surface by the probe liquids. The small hysteresis effects determined for the relatively rough poly $(1 \mathrm{H}, 1 \mathrm{H}, 2 \mathrm{H}, 2 \mathrm{H}$-perfluorodecyl methacrylate) films $\left(R_{a} 1.17 \mathrm{~nm}\right)$ imply that these structures are homogeneous with respect to van der Waals and/or hydrogen-bonded interactions.

The n-hexadecane contact angle is generally accepted as the index of oleophobicity. ${ }^{2}$ F or both melt-deposited samples which exhibited time-independent wetting behavior, poly $(1 \mathrm{H}, 1 \mathrm{H}, 2 \mathrm{H}, 2 \mathrm{H}$-perfluorododecyl methacrylate) and poly $(1 \mathrm{H}, 1 \mathrm{H}, 2 \mathrm{H}, 2 \mathrm{H}$-perfluorodecyl methacrylate), this contact angle was found to be $83^{\circ}$ and is identical to that previously reported for poly $(1 \mathrm{H}, 1 \mathrm{H}, 2 \mathrm{H}$, $2 \mathrm{H}$-perfluorododecyl acrylate). ${ }^{12}$ Previously, fluoropolymers have been identified ${ }^{30,31}$ with $n$-hexadecane values of $85^{\circ}$, but as for the poly $(1 \mathrm{H}, 1 \mathrm{H}, 2 \mathrm{H}, 2 \mathrm{H}$-perfluoroal $k y l$ acrylate)s, ${ }^{12}$ it is the combined effect of the hydrophobic $\left(125^{\circ}\right)$ and oleophobic nature of these poly $(1 \mathrm{H}, 1 \mathrm{H}, 2 \mathrm{H}, 2 \mathrm{H}$ perfluoroalkyl methacrylate)s that is responsible for the unusually low-surface-energy values associated with these materials. ${ }^{29,32-34}$

In accord with previous work, ${ }^{19}$ the results presented in Table 2 demonstrate that the nature of the pendent chain has a most profound effect in determining the surface energy of a polymeric material, with fluorosubstituted compounds exhibiting surface energies which are markedly lower than those of corresponding alkylsubstituted macromolecules. The relationship between the nature of the linking group and the length of the perfluorocarbon chain has also been elucidated by considering the time dependence of the wetting behavior; a long perfluorocarbon side chain is an essential element of the molecular design for such materials as 
it serves to mask the Lewis acid and Lewis base behavior of the linking moiety and, hence, inhibit the absorption of liquids by the bulk sample. ${ }^{12,17-19}$ The unanswered question concerned with the relative importance of backbone flexibility can be addressed by comparing the surface energies of the poly $(1 \mathrm{H}, 1 \mathrm{H}, 2 \mathrm{H}, 2 \mathrm{H}$ perfluoroalkyl methacrylate) film structures with those of the previously reported ${ }^{12-19}$ poly $(1 \mathrm{H}, 1 \mathrm{H}, 2 \mathrm{H}, 2 \mathrm{H}$-perfluoroalkyl acrylate)s. In view of the common surface organization features characterizing both classes of polymer films, the results presented in Table 2 demonstrate that, in marked contrast to previous literature reports, ${ }^{2,11}$ the presence of a flexible backbone is of little significance to the molecular design requirements for low-surface-energy polymers. I ndeed, although the acrylates, which possess an acidic $\alpha$-hydrogen, have a lower barrier to rotation than corresponding methacrylates, the surface energies determined for the latter class of materials are essentially identical to those reported for members of a directly analogous series of polymers belonging to the former class. ${ }^{19}$ Interestingly, the surface energy of poly $(1 \mathrm{H}, 1 \mathrm{H}, 2 \mathrm{H}, 2 \mathrm{H}$-perfluorodecyl diitaconate) ${ }^{35}$-a congener which contains two perfluoroalkyl chains per constitutional repeat unit, as opposed to one in poly $(1 \mathrm{H}, 1 \mathrm{H}, 2 \mathrm{H}, 2 \mathrm{H}$-perfluorodecyl acrylate) or poly$(1 \mathrm{H}, 1 \mathrm{H}, 2 \mathrm{H}, 2 \mathrm{H}$-perfluorodecyl methacrylate)-has also been determined at approximately $7.5 \mathrm{~mJ} \mathrm{~m}^{-2}$. Nevertheless, since the perfluorocarbon content may be high enough as to overwhel $m$ any effects of chain diffusion, it may also be appropriate to consider a series of copolymer systems in which the perfluoroalkyl chains are diluted.

3.3. Adhesion Force Measurements by AFM. Although contact angle goniometry is the method of choice for the determination of surface energies, atomic force microscopy may be a more readily accessible alternative. Atomic force microscopy can be used to measure the force of adhesion between polymer surfaces and an uncoated $\mathrm{Si}_{3} \mathrm{~N}_{4}$ AFM tip. ${ }^{36}$ The work of adhesion is related to the surface free energy of the polymer using J ohnson, Kendall, and Roberts (J KR) theory of adhesion mechanics. ${ }^{21,37}$ According to this model, the "pull-off" force, $F_{\text {ad, }}$ required to separate an AFM tip of radius $\mathrm{R}$ from a planar surface is given by

$$
\mathrm{F}_{\mathrm{ad}}=\frac{3}{2} \pi \mathrm{RW}_{\mathrm{SMT}}
$$

where

$$
\mathrm{W}_{\mathrm{SMT}}=\gamma_{\mathrm{SM}}+\gamma_{\mathrm{TM}}-\gamma_{\mathrm{ST}}
$$

$\mathrm{W}_{\mathrm{SMT}}$ is the thermodynamic work of adhesion for separating the sample and tip; $\gamma_{\mathrm{SM}}$ and $\gamma_{\mathrm{TM}}$ are the surface free energies of the sample (S) and tip (T), respectively, in contact with the medium $\mathrm{M}$; and, $\gamma_{\mathrm{ST}}$ is the interfacial surface free energy of the two interacting sol id surfaces. ${ }^{38}$ I ndeed, a correlation has been reported between work of adhesion, as determined from forcedistance curves, and surface free energies obtained from other techniques. ${ }^{39,40}$

Typical force-distance curves (tip retraction cycle only) obtained from the series of poly(perfluoroalkyl methacrylate) films under consideration are shown in Figure 3 with the mean forces of adhesion, as measured from the numerous pull-off curves, summarized in Table 3. In accord with results from the contact angle goni-

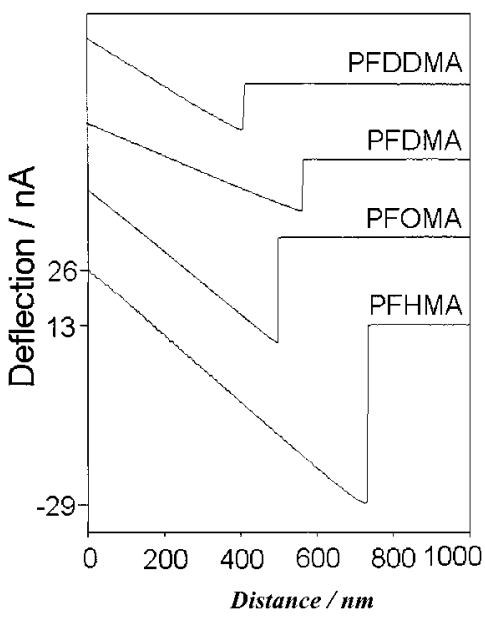

Figure 3. Typical force-distance curves (tip-retraction halfcycle) showing the adhesion force pull-off obtained from $\mathrm{a} \mathrm{Si}_{3} \mathrm{~N}_{4}$ AFM tip and a series of melt-formed poly(perfluoroalkyl methacrylate) films. The scaling on the vertical axis refers to the cantilever deflections measured at specific points on the force-distance curve obtained from the hexyl polymer (PFHMA). The curves obtained from other polymers are arbitrarily offset on the vertical axis from that of PFHMA. The differences in deflection between points where the tip is just adhered to the surface (in the case of PF HMA, at deflection -29 nA) and where the tip is suddenly released (at deflection $13 \mathrm{nA}$ ), together with the sensor response (gradient of the sloped, linear region of the curve, in $\mathrm{nA} \mathrm{nm}^{-1}$ ) and the experimentally determined cantilever spring constant $\left(0.034 \mathrm{~N} \mathrm{~m}^{-1}\right)$ are used to obtain the adhesion force. ${ }^{34}$

Table 3. Mean Forces of Adhesion As Measured from Pull-Off Curves (ca. 135 for Each Melt-Formed Polymer Film); the Nonfluorinated Analogue of PFDDMA. Poly(dodecyl methacrylate), Was Also Evaluated for Comparison ${ }^{\text {a }}$

\begin{tabular}{ccc}
\hline sample & mean adhesion $/ \mathrm{nN}$ & standard deviation $/ \mathrm{nN}$ \\
\hline PFDDMA & 7.1 & 2.7 \\
PFDMA & 8.1 & 0.7 \\
PFOMA & 9.2 & 3.2 \\
PFHMA & 17.8 & 1.7 \\
PDDMA & 80.1 & 4.9
\end{tabular}

a The chemical structures of polymers PFHMA, PFOMA, PFD$M A$, and PFDDMA are shown in Figure 1.

ometry experiments (Table 2), the adhesion forces between the tip and the polymer were found to be inversely proportional to thelength of the perfluoroalkyl chain; this observation translates particularly well for the progressively rougher higher homologues for which the determined mean adhesion values foll ow the trend but are within one standard deviation of each other. F or the lower analogue, PFHMA, the absolute value of the measured force of adhesion does not correlate linearly with the determined surface energy. Presumably, plasticization of the this homologue by water (the experiments needed to be performed under double-distilled water in order to eliminate static charges and capillary effects; the latter are 1-2 orders of magnitude greater than specific molecular level interactions ${ }^{21,38,41}$ ) is responsible for this effect. Observations of the dimensions of drops of water on the surface of these materials confirmed that this liquid is absorbed by both PFOMA and, at a faster rate, PFHMA films. The same liquid does not penetrate the surface of films prepared from the higher homologues, PFDMA and PFDDMA.

It is characteristic that, over the entire sensor range, the force of adhesion appears to be independent of the applied load exerted by the tip. This observation is in 
marked contrast to previous literature reports 36,42 and may be accounted for in terms of the inability of the very flexible cantilever to effect a significant indention of the polymer surfaces. Nonetheless, this finding may be taken as evidence that the adhesi on forces measured in this study reflect the magnitude of the molecularlevel forces operating between the polymer and the tip, rather than being a mere artifact of a physical indentation-release interaction.

This work emphasizes the accessibility of the AFM method for the determination of surface energies but also highlights its weaknesses. In particular, although, in principle, the work of adhesion ( $\left.\mathrm{W}_{\mathrm{SMT}}\right)$ for a specific substrate-medium-tip (SMT) system can be determined from measured adhesion forces $\left(F_{a d}\right)$ for a tip whose radius ( $R$ ) is precisely known (eq 4), the interfacial surface energies $\left(\gamma_{S M}, \gamma_{T M}, \gamma_{S T}\right)$ that contribute to this property cannot be resolved (eq 5) unless the force measurements are carried out in a number of liquids. This is often difficult for polymeric materials because of solubility and/or liquid-absorption phenomena; an attempt to work in a perfluorodecalin environment ${ }^{43}$ did not prove successful. Thus, since all the experiments reported in this study were carried out in the same medium and using the same AFM tip, the $\gamma_{T M}$ term must be constant. However, as water has been found to penetrate the film structures prepared from the lower poly(perfluoroalkyl methacrylate)s homologues, PFHMA and PFOMA, no meaningful conclusi ons can be drawn regarding the relationship between relative force of adhesion and length of pendent perfluoroalkyl chain.

\section{Conclusions}

The surface energies of a homologous series of poly(perfluoroalkyl methacrylate) film structures have been determined by contact angle goniometry, and the results were compared and contrasted with adhesion force measurements obtained using AFM. In parallel, the surface organization phenomena characterizing these films were examined in light of XPS analysis results. The work revealed that, for low-surface-energy polymers with a comblike structure, the presence of a flexible backbone is of no significance to the molecular design requirements as long as the concentration of pendent perfluorocarbon chains is sufficiently high to mask any chain-diffusion-related effects.

Acknowledgment. The financial support of this work by NERC (P.G.; GST/02/1443) and EPSRC (P.J .E.; GR/M 31712) is gratefully acknowledged.

\section{References and Notes}

(1) Tunney, M. M.; Gorman, S. P.; Patrick, S. Rev. Med. Microbiol. 1996, 7, 195.

(2) Kobayashi, H.; Owen, M. J . Trends Polym. Sci. 1995, 3, 10.

(3) Cuddihy, E. F. In Particles on Surfaces 1: Detection, Adhesion and Removal; Mittal, K., Ed.; Plenum Press: New York, 1988; pp 91-111. Linder, E. In Recent Developments in Biofouling Control; Thompson, M., Ed.; Elsevier: Rotterdam, 1994; pp 305-311.

(4) Tsibouklis, J .; Stone, M.; Thorpe, A. A.; Graham, P.; Peters, V.; Heerlien, R.; Smith, J. R.; Green, K. L.; Nevell, T. G. Biomaterials 1999, 20, 1229.

(5) Wu, S. H. Polymer Interfaces and Adhesion; Marcel Dekker: New York, 1982.

(6) Lau, Y. W.; Burns, C. M. J . Polym. Sci., Polym. Phys. Ed. 1974, 12, 431.

(7) Bernett, M. K.; Zisman, W. A. J . Phys. Chem. 1960, 64, 1292.
(8) Dettre, R. H.; J ohnson, J r., R. E. J . Colloid Interface Sci. 1966, 21, 367.

(9) Dettre, R. H.; J ohnson, J r., R. E. J . Colloid Interface Sci. 1969, 31, 568.

(10) Glennon, D.; Smith, J . R.; Cox, P. A.; Ewen, R.; Nevell, R. T.; Nevell, T. G.; Tsibouklis, J.J . Mater. Sci. 1998, 33, 3511.

(11) Owen, M. J . Comments I norg. Chem. 1988, 7, 195.

(12) Stone, M.; Nevell, T. G.; Tsibouklis, J . Mater. Lett. 1998, 37, 102.

(13) Thomas, R. R.; Anton, D. R.; Graham, W. F.; Darmon, M.J .; Sauer, B. B.; Stika, K. M.; Swartzfager, D. G. Macromolecules, 1997, 30, 2883.

(14) Sheiko, S.; Lermann, E.; Moller, M. Langmuir, 1996, 12, 4015.

(15) Ciardelli, F.; Aglietto, M.; diMirabello, L. M.; Passaglia, E.; Giancristoforo, S.; Castelvetro, V.; Ruggeri, G. Prog. Org. Coat. 1997, 32, 43.

(16) Tirelli, N.; Ahumada, O.; Suter, U. W.; Menzel, H.; Castelvetro, V. Macromol. Chem. Phys. 1998, 199, 2425.

(17) Thorpe, A. A.; Young, S. A.; Nevell, T. G.; Tsibouklis, J . Appl Surf. Sci. 1998, 136, 99.

(18) Thorpe, A. A.; Nevell, T. G.; Tsibouklis, J . Appl. Surf. Sci. 1999, 137, 1.

(19) Tsibouklis, J .; Stone, M.; Thorpe, A. A.; Graham, P.; Ewen, R. J .; Nevell, T. G. Langmuir 1999, 15, 7076.

(20) Kassis, C. M.; Steehler, J . K.; Betts, D. E.; Guan, Z. B.; Romack, T. J .; DeSimone, J. M.; Linton, R. W. Macromolecules, 1996, 29, 3247.

(21) Israelachvili, J. N. Intermolecular and Surface Forces, 2nd ed.; Academic Press: London, 1992.

(22) Cleveland, J . P.; Manne, S.; Bocek, D.; Hansma, P. K. Rev. Sci. Instrum. 1993, 64, 75.

(23) Kaye, G. W. C., Laby T. H., Eds.; Table of Physical and Chemical Constants, 15th ed.; Longman Scientific and Technical: Harlow, 1992.

(24) Lide, D. R. Ed.; Handbook of Chemistry and Physics, 76th ed.; CRC Press: Boca Raton, FL, 1995.

(25) Good, R. G.; van Oss, C. J. In Modern Approaches to Wettability: Theory and Applications; Schrader, M. E., Loeb, G., Eds.; Plenum Press: New York, 1991; pp 1-27.

(26) Good, R. G.; Chaudhury, M. K.; van Oss, C. J . In Fundamentals of Adhesion; Lee, L. H., Ed.; Plenum Press: New York, 1991; pp 153-172.

(27) Drummond, C. J .; Chan, D. Y. C. Langmuir 1997, 13, 3890.

(28) Wagner, C. D.; Davis, L. E.; Zeller, M. V.; Taylor, J. A.; Raymond, R. H.; Gale, L. H. Surf. Interface Anal. 1981, 3, 211.

(29) Wang, J .; Ober, C. K. Macromolecules 1997, 30, 7560.

(30) Kobayashi, H. Makromol. Chem. 1993,194, 2569.

(31) McLain, S. J .; Sauer, B.; Firment, L. Polym. Prepr., Am. Chem. Soc., Div. Polym. Chem. 1993, 34, 666.

(32) F ox, H. W.; Zisman, W. A. J . Colloid Interface Sci. 1950, 5, 514.

(33) Suzuki, M.; Saotome, Y.; Yanagisawa, M. Thin Solid Films 1988, 160, 453

(34) Nakahama, H.; Miyato, S.; Wang, T.; Tasaka, S. Thin Solid Films 1986, 141, 165.

(35) Pullin, R. A.; Nevell, T. G.; Tsibouklis, J . Mater. Lett. 1999, 39, 142.

(36) Weisenhorn, A. L.; Maivald, P.; Butt, H.-J .; Hansma, P. K. Phys. Rev. B 1992, 45, 11226.

(37) J ohnson, K. L.; Kendall, K.; Roberts, A. D. Proc. R. Soc. London, Ser. A 1971, 324, 301.

(38) Noy, A.; Vezenov, D. V.; Lieber, C. M. Annu. Rev. Mater. Sci. 1997, 27, 381.

(39) Kawai, A.; Nagata, H.; Takata, M. J pn. J . Appl. Phys. 1992, 31, L977.

(40) Kawai, A.; Nagata, H.; Morimoto, H.; Takata, M. In Surface Modification Technol ogies VII; Proc. 7th Int. Conf.; Sudarshan, T. S., I shizaki, K., Takata, M., Kamata, K., E ds.; Sanjo, Niigata, J apan, 31 Oct-2 Nov 1993.

(41) Eaton, P. J .; Graham, P.; Smith, J . R.; Smart, J . D.; Nevell, T. G.; Tsibouklis, J. Langmuir, in press.

(42) Burnham, N. A.; Colton, R. J .; Pollock, H. M. Nanotechnology 1993, 4, 64.

(43) Feldman, K.; Tervoort, T.; Smith, P.; Spencer, N. D. Langmuir 1998, 14, 372.

MA0008185 